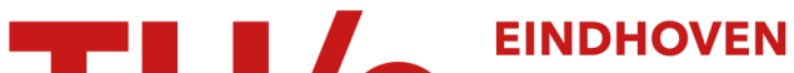 UNIVERSITY OF TECHNOLOGY
}

\section{Direct atomistic modelling of deformed polymer glasses}

\section{Citation for published version (APA):}

Lyulin, A. V., \& Michels, M. A. J. (2008). Direct atomistic modelling of deformed polymer glasses. In A. Co, G. L. Leal, R. H. Colby, \& A. J. Giacomin (Eds.), Proceedings of the XVth International Congress on Rheology : the Society of Rheology 80th annual meeting (ICR 2008), 3-8 August 2008, Monterey (California) (pp. 1330-1332). (AIP Conference Proceedings; Vol. 1027). American Institute of Physics. https://doi.org/10.1063/1.2964563

DOI:

10.1063/1.2964563

Document status and date:

Published: 01/01/2008

\section{Document Version:}

Publisher's PDF, also known as Version of Record (includes final page, issue and volume numbers)

\section{Please check the document version of this publication:}

- A submitted manuscript is the version of the article upon submission and before peer-review. There can be important differences between the submitted version and the official published version of record. People interested in the research are advised to contact the author for the final version of the publication, or visit the $\mathrm{DOI}$ to the publisher's website.

- The final author version and the galley proof are versions of the publication after peer review.

- The final published version features the final layout of the paper including the volume, issue and page numbers.

Link to publication

\section{General rights}

Copyright and moral rights for the publications made accessible in the public portal are retained by the authors and/or other copyright owners and it is a condition of accessing publications that users recognise and abide by the legal requirements associated with these rights.

- Users may download and print one copy of any publication from the public portal for the purpose of private study or research.

- You may not further distribute the material or use it for any profit-making activity or commercial gain

- You may freely distribute the URL identifying the publication in the public portal.

If the publication is distributed under the terms of Article 25fa of the Dutch Copyright Act, indicated by the "Taverne" license above, please follow below link for the End User Agreement:

www.tue.nl/taverne

Take down policy

If you believe that this document breaches copyright please contact us at:

openaccess@tue.nl

providing details and we will investigate your claim. 


\title{
Direct Atomistic Modelling of Deformed Polymer Glasses
}

\author{
Alexey V. Lyulin and M.A.J. Michels \\ Group Polymer Physics, Eindhoven Polymer Laboratories, Technische Universiteit Eindhoven, \\ P.O. Box 513, 5600 MB Eindhoven, The Netherlands \\ and Dutch Polymer Institute, P.O. Box 902, 5600 AX Eindhoven, The Netherlands
}

\begin{abstract}
We use molecular-dynamics computer simulations to explore the influence of thermal and mechanical history of typical glassy polymers, atactic polystyrene (PS) and (bis)phenol A polycarbonate (PC), on their deformation. Polymer stress-strain and energy-strain developments have been followed for different deformation velocities, also in closed extension-recompression loops. The latter simulate for the first time the experimentally observed mechanical rejuvenation and overaging of polymers. Energy partitioning reveals essential differences between mechanical and thermal rejuvenation. All results are qualitatively interpreted by considering the ratio's of relevant timescales: for cooling down, for deformation, and for intrinsic segmental relaxation.
\end{abstract}

Keywords: molecular dynamics, glass transition, mechanical deformation.

PACS: 62.20.Fe, 83.10.Mj, 64.70.Pf

\section{INTRODUCTION}

Severe post-yield strain softening for PS is usually connected to the process of structural relaxation (or "physical aging") [1]. After the yield point the stress drops to a value which is independent of aging time, and it was concluded that mechanical extension erases the polymer thermal history [2]. A molecular understanding of aging via structural relaxation and strain softening is still lacking, and even more so for polymers. The sum of the aging and deformation times compared to the internal relaxation time is what finally determines the yield stress of low-molecular-weight glasses, as has been shown recently by molecular-dynamic (MD) simulations [3].

In the present paper we perform direct atomistic MD modelling of the processes of deformation, mechanical rejuvenation and overaging (acceleration of aging) for the two typical polymer glass formers, PS and PC, which differ in the time scales of their segmental relaxation, each case we prepared different thermal histories (annealing and quenching). We show that the differences observed under deformation can be understood in terms of the ratios of three different characteristic time scales: $\tau_{c}$, the characteristic time of cooling down from high-temperature melt, $\tau_{\beta}$, the relaxation time of segmental motions within the cage formed by the neighboring polymer segments and, finally, $\tau_{y}$, the time to reach the yield peak. We also show that mechanical and thermal rejuvenation involve different segmental processes, and are indeed different, in agreement with recent experimental observations [4].

United-atom models for non-entangled polymer melts are used; they have been described in detail by Lyulin et al. [5]. Briefly, constant temperature-pressure NPT MD simulations are carried out for a system of 4-8 atactic PS chains of $N=80-160$ monomers each, and 64 PC chains of $N=10$ monomers. The size of the PS and PC samples is comparable to or even larger than the samples of the previous computational studies [6] for much simpler models. A Berendsen barostat and a collisional thermostat have been used. Five independent samples are created for each polymer and the final results are averaged. The samples are equilibrated at $T=540 \mathrm{~K}$ (highly mobile melt) for $10 \mathrm{~ns}$. The quality of the equilibration is checked by standard methods.

After equilibration continuous cooling is implemented, with cooling rates spanning more than three decades in time: from more than $30 \mathrm{~K} / \mathrm{ps}$ (simulated quenching) to $0.01 \mathrm{~K} / \mathrm{ps}$ (simulated annealing). These cooling rates are extremely fast from an experimental point of view. However, the glass-transition temperature increases only logarithmically with cooling rate [5], and realistic values of $T_{\mathrm{g}}$ can be obtained by extrapolating the simulated data 
towards experimental cooling rates. The PS and PC samples are cooled down to the corresponding glass transition temperatures ( $T_{\mathrm{g}}=375 \mathrm{~K}$ for PS and $T_{\mathrm{g}}=435 \mathrm{~K}$ for PC) [5], and to the room temperature $T=300 \mathrm{~K}$.

\section{RESULTS AND DISCUSSION}

For both non-deformed polymers the distribution functions of the segmental orientational relaxation times reveals the existence of two different processes: relaxations within the cage, $\beta$ motions, and $\alpha$ relaxation of the cage itself. The simulated $\beta$ relaxation for PS monomers is rather fast (time scale $\tau_{\beta}$ is about 50 ps), and is well separated from the $\alpha$ relaxation (time scale $\tau_{\alpha}$ for both polymers is above $100 \mathrm{~ns}$ ). The simulated $\beta$ relaxation for PC monomers is slower, $\tau_{\beta}$ is about 500 ps. Uniaxial deformation is applied with different deformation velocity (from $0.05 \AA$ /ps to $0.0005 \AA$ /ps) at $T=300 \mathrm{~K}$ to polymer samples prepared by the cooling procedure explained above. The deformation was simulated in the NPT ensemble, with the same barostat and thermostat as earlier, and was applied along one of the Cartesian axes (X, Y or $\mathrm{Z}$ ) to each of the five samples for each polymer. Extensionrecompression loops have been applied to annealed (and quenched, not shown) samples of PS and PC with different velocities, Fig. 1 and 2. The energy at maximum strain strongly increases with strain rate, i.e. with $\tau_{y}^{-1}$; this is logical since in all simulations $\tau_{y}$ (time for forced out-of-cage-motion) is much smaller than the time $\tau_{\alpha}$ (time for cage relaxation), and $\alpha$ processes are unable to relax the corresponding barrier for this out-of-cage motion. The energy after recompression is a combination of energy increase by forced out-of-cage motion, and possible energy recovery under $\beta$ relaxation. For annealed PS it is significantly higher than the original energy, so the polymer appears "rejuvenated". Upon recompressing PS relaxes its energy on the timescale of the $\beta$ motion, $50 \mathrm{ps,} \mathrm{after}$ which the energy increases again since new barriers will have formed; the "rejuvenating" PS will thus explore a different part of phase space (see below, Fig. 3). For annealed and stretched PC under the same deformation

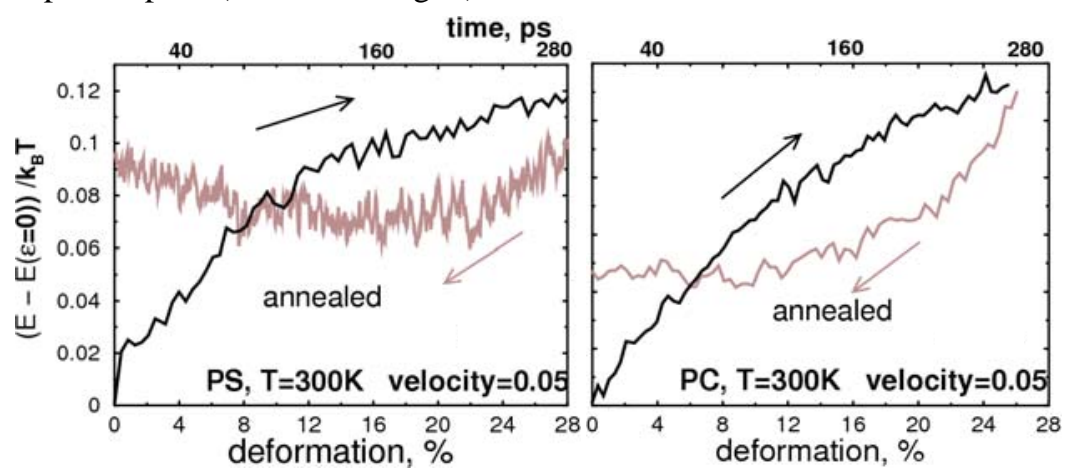

FIGURE 1. Energy evolution during closed deformation-recompression loops for annealed polymers. Temperatures and deformation velocities (in $\AA / p s$ ) are indicated. Results demonstrate mechanical rejuvenation.

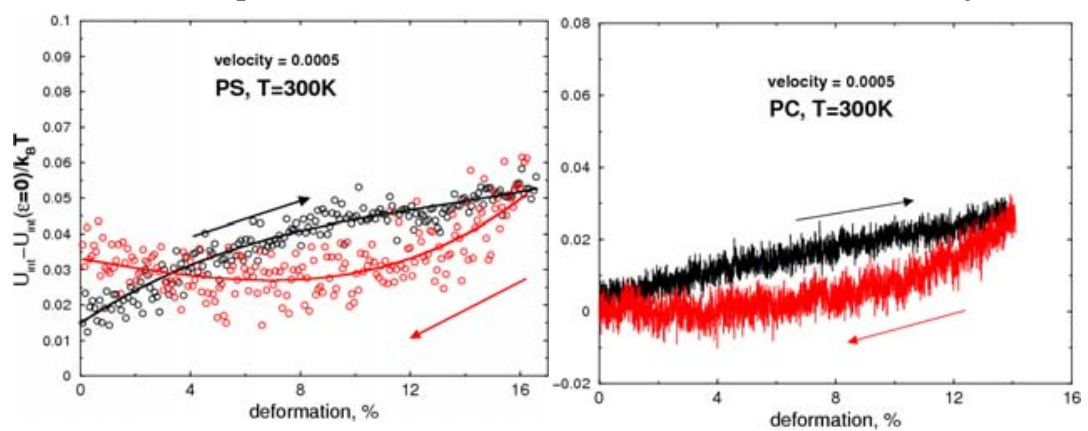

FIGURE 2. Energy evolution during closed deformation-recompression loops for annealed polymers. Temperatures and deformation velocities (in $\AA / p s$ ) are indicated. Results demonstrate mechanical rejuvenation for PS and some overaging for PC. 
velocity the recompression time is shorter than the time of $\beta$ motion, $500 \mathrm{ps}$, and no significant new barriers seem to appear. At the lowest deformation velocity the annealed and stretched PC even decreases in energy after recompression, Fig. 2, i.e. it overages, also due to the low energy at maximum strain. Such an overaging is observed in recent experiments on PC under long-term loading [7] and in simulations of a binary Lennard-Jones liquid [6].

Partitioning of the energy between different force-field contributions clearly shows that the energy differences upon cooling (quenched minus annealed), or overaging (quenched minus end-of-loop), or mechanical rejuvenation (end-of-loop minus annealed) may be very different, see Fig. 3. For PC the thermal rejuvenation is for more than $80 \%$ due to weaker Van der Waals interactions, while the difference after a mechanical rejuvenation is for about $40 \%$ due to increased torsion of the chains. The partitioning of the energy for mechanically overaged initially quenched PC is very similar to the partitioning of the energy for thermally rejuvenated polymer, so $\beta$ relaxations may indeed play the same role in both. For PS the in-monomer (stretching, bending, torsion) and inter-monomer (van der Waals) contributions are roughly equally partitioned. In their recently reported MD simulations of a model polymer glass Capaldi et al. [8] also observed pronounced changes in the torsional energy under the deformation. The much more diverse partitioning for PS in the various simulations indeed points at exploration of different parts of phase space.

The main message of our study is that differences in stress-strain and energy-strain curves between the polymers could be interpreted in terms of ratios between the relevant time scales: the times for cooling down from the hightemperature melts, the times for deformation up to the yield point (forced out-of-cage motion), and the $\beta$ -

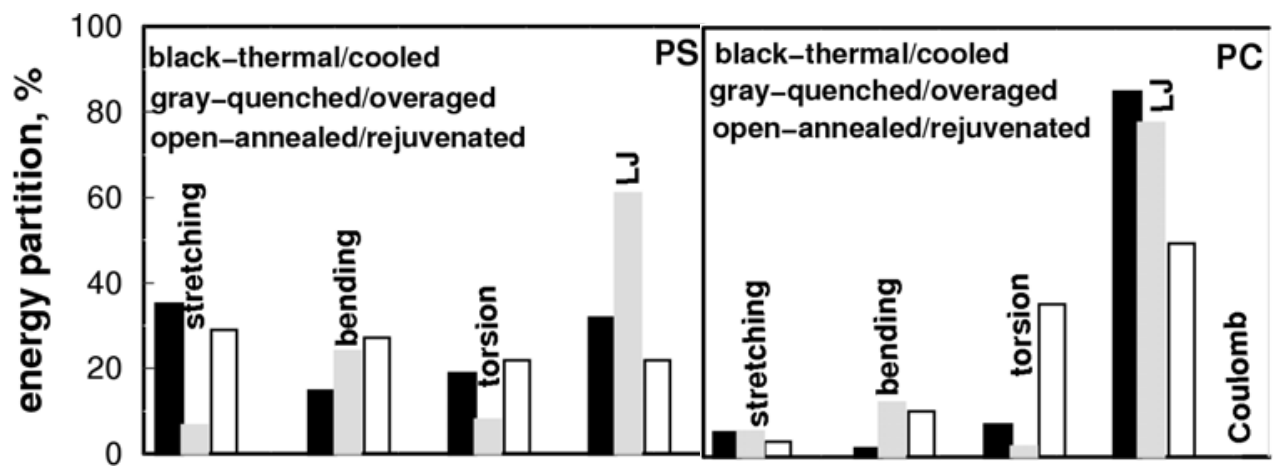

FIGURE 3. Partitioning of the final-energy difference for three cases $(T=300 \mathrm{~K})$ : quenching vs. annealing, black; quenching vs. additional mechanical overaging (deformation velocity $0.05 \AA / p s$ ), gray; annealing and mechanically rejuvenation (deformation velocity $0.005 \AA / p s$ ) vs. annealing, open.

relaxation times. The results give insight into the energy landscapes and relaxation mechanisms of the deforming polymer glasses, in terms of differences between quenched and annealed samples, between deformations at different rates, and between thermal and mechanical rejuvenation. Qualitatively these conclusions can be translated towards upscaled experimental conditions.

\section{ACKNOWLEDGMENTS}

This work is part of the research program of the Dutch Polymer Institute (project 487) and was partly sponsored by the Stichting Nationale Computerfaciliteiten (NCF). Grateful acknowledgement is made to Dr. Leon Govaert (TU Eindhoven) for many useful discussions.

\section{REFERENCES}

1. L.C.E. Struik, Physical Aging in Amorphous Polymers and Other Materials, Elsevier, Amsterdam, 1978.

2. O.A. Hasan and M.C. Boyce, Polymer 34, 5085 (1993).

3. J. Rottler and M.O. Robbins, Phys. Rev. Lett. 95, 225504 (2005).

4. G.B. McKenna, J. Phys 15, S737 (2003).

5. A.V. Lyulin, B. Vorselaars, M.A. Mazo, N.K. Balabaev and M.A.J. Michels, Europhys. Lett. 71, 618 (2005).

6. D.J. Lacks and M.J. Osborne, Phys. Rev. Lett. 93, 255501 (2004).

7. E.T.J. Klompen, T.A.P. Engels, L.E. Govaert and H.E.H. Meijer, Macromolecules 38, 6997 (2005).

8. F.M. Capaldi, M.C. Boyce and G.C. Rutledge, Phys. Rev. Lett. 89, 175505 (2002). 